\title{
DESARROLLO, IDENTIDAD Y PODER EN LAS COMUNIDADES INDÍGENAS DE CHIMBORAZO (ECUADOR)
}

\section{DEVELOPMENT, IDENTITY AND POWER IN THE INDIGENOUS COMMUNITIES OF CHIMBORAZO (ECUADOR)}

\author{
Luis Alberto Tuaza \\ Universidad Nacional de Chimborazo
}

\section{Resumen.}

El artículo analiza los alcances de la intervención de las Organizaciones No Gubernamentales de Desarrollo y las instituciones del gobierno local, provincial y nacional en el fortalecimiento de la identidad indígena y la articulación de un nuevo tipo de poder en la emergencia de las organizaciones y el protagonismo de los indígenas en el campo del desarrollo, desde el acercamiento etnográfico a las comunidades. El estudio concluye que la intervención de las instituciones de cooperación no afianza propiamente la identidad étnica, ni articula el protagonismo, aunque promueva la emergencia de las organizaciones.

Palabras clave.

Desarrollo; Indígenas; Identidad y poder; Ecuador.

\section{Abstract.}

This article analyzes the impacts of the interventions of development Non-Governmental Organizations and local, provincial and national government institutions in strengthening indigenous identity and in articulating a new type of power through the emergence of indigenous organizations and leadership in the field of development. Using an ethnographic approach, the study concludes that the intervention of cooperation institutions does not strengthen ethnic identity or articulate leadership, but it does promote the emergence of organizations. 


\section{Key Words.}

Development; Indigenous; Identity and power; Ecuador.

\section{Introducción}

De acuerdo a la retórica generalizada de los funcionarios de las Organizaciones No Gubernamentales de Desarrollo (ONGD) y las instituciones del gobierno local, provincial y nacional que operan actualmente en el medio rural, las acciones emprendidas por sus instituciones, harían posible, por un lado el fortalecimiento de la identidad indígena, y por otro lado, permitirían la emergencia de un nuevo tipo de poder, caracterizado por la emergencia de las organizaciones y el protagonismo de los indígenas, en contraste a las antiguas formas de dominación (Ibarra, 2002), asociadas al régimen de hacienda (Bretón, 2012). Gracias a la cooperación al desarrollo, los indígenas que en el pasado estuvieron, "inconscientes" de su identidad cultural, y sometidos a los abusos de los hacendados, los mestizos de los centros parroquiales y las autoridades del gobierno, habrían llegado, por fin a sentirse dichosos de ser indios y a vivir libremente en organización. Mi hipótesis es que más allá de afianzar la identidad, de fortalecer las organizaciones y generar el protagonismo de los indígenas, el desarrollo posibilita la articulación de nuevas formas de poder, por las que los actores considerados benefactores, capitalizan gratitudes de los beneficiarios, garantizando así, el triunfo electoral en algunos casos, y en otros, manteniendo la capacidad de maniobra sobre las poblaciones indígenas. ¿Cuáles son los alcances de la cooperación al desarrollo en el medio rural, en cuanto a la identidad, la articulación de un nuevo tipo de poder que se explicitaría en la emergencia de las organizaciones y en el protagonismo de los indígenas? ¿Cuáles son los mecanismos que utilizan las ONGD y las instituciones de gobierno para afianzar su intervención en los espacios indígenas? ¿Qué tipo de configuraciones del poder aparecen en el día a día de las comunidades? son las preguntas a las que se busca responder en el presente artículo, desde el acercamiento etnográfico a las experiencias de desarrollo en las comunidades indígenas del cantón Guamote de la provincia de Chimborazo, Ecuador.

\section{Los alcances de la cooperación al desarrollo en el medio rural}

A diferencia de las primeras intervenciones del aparato del desarrollo en el medio rural, en las que los temas de identidad y el poder, no aparecen, en estos últimos años, las mencionadas palabras legitiman las acciones que ejecutan las ONGD y las instituciones del gobierno local, provincial y nacional en las comunidades indígenas. En el pasado, ni la Misión Andina, programa internacional de desarrollo diseñado por las Naciones Unidas y dirigida por la Organización Internacional de Trabajo que buscaba integrar a la población indígena a la sociedad blanco - mestiza (Bretón, 2001), ni el Fondo de Desarrollo Rural Marginal (FODERUMA), ni los proyectos de Desarrollo Rural Integral (DRI) tocaron directamente los temas de identidad y de poder. Estos enfatizaron en la necesidad de construir el andamiaje organizativo (Bretón, 2001), 
como un mecanismo de concretar exitosamente los proyectos de desarrollo, a fin de promover el crecimiento económico, pero no tenían el interés de fortalecer la identidad indígena, ni cuestionar el poder dominante de la hacienda, que aún operaba en las décadas de los sesenta, setenta y ochenta del siglo pasado. Lo que, es más, en los imaginarios de estos organismos de cooperación, la identidad indígena aludía a lo tradicional, al atraso (Santana, 1995) y constituía una seria amenaza a la prosperidad que prometía el desarrollo.

Años más tarde, ya en la década de los noventa, las ONGD y las instituciones del gobierno, en contraste al menosprecio de la identidad indígena de otrora y el olvido del cuestionamiento de los poderes tradicionales, pusieron en el centro de la articulación discursiva, orientada a legitimar sus intervenciones en los espacios indígenas, precisamente, la identidad y el poder. En esta perspectiva se habló de etnodesarrollo, de los "términos como 'empoderamiento', 'sostenibilidad', 'identidad', 'capital social', 'interculturalidad', etc.' (Palenzuela, 2011). Pero, como ha demostrado Bretón (2001), tan solo cambiaron los adjetivos del desarrollo, más no, las prácticas de intervención.

A mediados de la primera década del 2000, específicamente durante los primeros años del gobierno de Rafael Correa (2006 - 2008), y en el contexto dela elaboración de la nueva constitución (2008), apareció en el Ecuador, el término kichwa sumak kawsay, y en Bolivia, la expresión aymara suma qamaña, igualmente en el marco de la redacción de la nueva carta magna en ese país. Estos dos términos traducidos al español, serían el buen vivir, y en el campo del desarrollo expresarían "una forma alternativa de entender el desarrollo" (...) "presuntamente anclada en los 'saberes ancestrales' y las cosmovisiones indígenas que tendrían que orientar, según sendas cartas magnas, la acción del Estado y los poderes públicos" (Bretón, Cortez y García, 2014: 9), superando así, las antiguas propuestas de desarrollo enfatizadas en el crecimiento económico y en las prácticas depredadoras que amenazan la naturaleza. De aquellos años, hasta la fecha, ha corrido mucha tinta para explicar el sumak kawsay, desde las posiciones esencialistas (León, 2010; Simbaña, 2011; Acosta, 2011), hasta las más críticas (Viola, 2014; Cuestas-Caza, 2018).

De acuerdo a los ideólogos del sumak kawsay, o el Buen vivir, este término sería un concepto plural y multidimensional, enmarcado en la renovación de la crítica al desarrollo, basada en una ética propia que reconoce los valores intrínsecos de la naturaleza y el rechazo al desarrollismo tradicional, que concibe al progreso en términos exclusivamente economicistas (Acosta, 2009; 2010), que "implica mejorar la calidad de la vida de la población, desarrollar capacidades y potencialidades; contar con un sistema económico que promueva la igualdad, a través de la redistribución social y territorial de los beneficios del desarrollo" (Larrea, 2010: 22); que "exige una reorganización y nuevos enfoques en el modelo político - económico, lo que transformaría a su vez no solo a la sociedad, sino y sobre todo al Estado" (Simbaña, 2011: 223). Para Ramírez, el sumak kawsay es "la satisfacción de las necesidades, la consecución de una calidad de vida y muerte dignas, el amar y ser amado, y el florecimiento saludable de todos, en paz y armonía con la naturaleza, para la propagación de las culturas humanas y de la biodiversidad" (Ramírez, 
2010: 61). En conexión con estas afirmaciones, Prada (2011), sostiene que el sumak kawsay o el buen vivir "desde la comprensión y experiencia de vida de pueblos indígena - campesinos, expresan un sentido de satisfacción al lograr el ideal de alimentar y nutrir a la comunidad con la producción propia" (Prada, 2001: 229), que posibilitaría el equilibrio entre las fuerzas de la naturaleza y la mancomunidad social.

El sumak kawsay sería también, la noción que expresa el tránsito del desarrollo al posdesarrollo por medio de la crítica, que conduce a la búsqueda de alternativas, muchas de ellas presentes en las sabidurías ancestrales de los pueblos indígenas, supondría el movimiento a un mundo totalmente diferente que supera la noción del crecimiento económico y las prácticas extractivistas (Gudynas, 2017), que permite comprender la vida, en nuevas ontologías relacionales de armonía con la naturaleza, vida que según Arturo Escobar sería el "conjunto interminable de formas y entidades que componen el pluridiverso -desde lo biofísico a lo humano y lo sobrenatural- y los procesos por lo que viene a ser" (Escobar, 2012: 40).

En sintonía con los discursos de desarrollo presentes en el debate académico, político y económico, en Guamote, las ONGD y las instituciones del gobierno municipal, provincial y nacional afirman promover los proyectos de desarrollo, inspirados en el etnodesarrollo, la idea del empoderamiento, el capital social (Bebbintong y Torres, 2001), la sostenibilidad y el sumak kawsay, a través de los cuales, estarían ayudando a fortalecer la identidad indígena y a reforzar el poder de la comunidad en la toma de decisiones y la resolución de los conflictos, por medio de la creación de las organizaciones y el protagonismo de los indígenas.

Tabla 1. ONGD operando en Guamote (Chimborazo) entre 2005 y 2018

\begin{tabular}{|l|l|l|}
\hline ONGD & Actividades & Zonas \\
\hline $\begin{array}{l}\text { Fundación Mujer y } \\
\text { Familia Andina }\end{array}$ & $\begin{array}{l}\text { Promoción de cadenas de } \\
\text { comercialización de la quinua y otros } \\
\text { granos andinos, talleres de capacitación } \\
\text { de las mujeres, liderazgo y fortalecimiento } \\
\text { comunitario. }\end{array}$ & $\begin{array}{l}\text { Comunidades de Atapo, Poma- } \\
\text { chaca, los Tipines y Galte. }\end{array}$ \\
\hline Plan Internacional & $\begin{array}{l}\text { Erradicación de la violencia infantil, } \\
\text { formación de los defensores de los } \\
\text { derechos de los niños, construcción de } \\
\text { baterías sanitarias, mejoramiento de la } \\
\text { infraestructura educativa y entrega de } \\
\text { becas escolares. }\end{array}$ & $\begin{array}{l}\text { Comunidades de la matriz } \\
\text { Guamote }\end{array}$ \\
\hline
\end{tabular}




\begin{tabular}{|c|c|c|}
\hline $\begin{array}{l}\text { Acción Integral } \\
\text { Guamote }\end{array}$ & $\begin{array}{l}\text { Agroecología, conservación de los } \\
\text { páramos, capacitación de la comunidad } \\
\text { en agroecología y la protección de los } \\
\text { páramos, entrega de créditos. }\end{array}$ & $\begin{array}{l}\text { Comunidades de Chanchan y } \\
\text { Tiocajas }\end{array}$ \\
\hline $\begin{array}{l}\text { Ayllukunapak Tan- } \\
\text { danakuyta Mas- } \\
\text { hkashpa }\end{array}$ & $\begin{array}{l}\text { Producción y comercialización de la papa } \\
\text { y granos andinos, entrega de créditos. }\end{array}$ & $\begin{array}{l}\text { Comunidades de Tejar y Mayo- } \\
\text { razgo }\end{array}$ \\
\hline Visión Mundial & $\begin{array}{l}\text { Protección y desarrollo del potencial de } \\
\text { la niñez y adolescencia, mejoramiento } \\
\text { de los servicios de agua, cursos sobre } \\
\text { los derechos de los niños y de los } \\
\text { adolescentes, y entrega de becas. }\end{array}$ & $\begin{array}{l}\text { Comunidades de Palmira y } \\
\text { Cebadas }\end{array}$ \\
\hline Fundación Heifer & $\begin{array}{l}\text { Agroecología, crianza de camélidos } \\
\text { Andinos, cuidado de la salud, soberanía } \\
\text { alimentaria, fortalecimiento de las } \\
\text { prácticas culturales y la identidad, } \\
\text { Creación de cadenas de comercialización. }\end{array}$ & $\begin{array}{l}\text { Comunidades de Palmira y La } \\
\text { Matriz }\end{array}$ \\
\hline $\begin{array}{l}\text { Compasión Inter- } \\
\text { nacional }\end{array}$ & $\begin{array}{l}\text { Patrocinio de niños, programas de } \\
\text { sobrevivencia infantil y desarrollo de } \\
\text { liderazgo. }\end{array}$ & Comunidades de La Matriz \\
\hline Fundación Esquel & Construcción de aulas escolares. & $\begin{array}{l}\text { Comunidad de Chismaute y } \\
\text { Pomachaca }\end{array}$ \\
\hline Free The Children & Construcción de aulas y paneles solares & $\begin{array}{l}\text { Comunidades Chismaute y San } \\
\text { Miguel de Pomachaca }\end{array}$ \\
\hline $\begin{array}{l}\text { Fundación Minga } \\
\text { para la Acción Ru- } \\
\text { ral y la Coopera- } \\
\text { ción (MARCO) }\end{array}$ & $\begin{array}{l}\text { Agroforestación, manejo de páramos y } \\
\text { entrega de créditos. }\end{array}$ & $\begin{array}{l}\text { Comunidades de La Matriz y } \\
\text { Cebadas }\end{array}$ \\
\hline
\end{tabular}




\begin{tabular}{|l|l|l|}
\hline Acción Rural & $\begin{array}{l}\text { Créditos agropecuarios y asesoría } \\
\text { veterinaria. }\end{array}$ & Comunidades de La Matriz \\
\hline $\begin{array}{l}\text { Escuelas Radiofó- } \\
\text { nicas Populares }\end{array}$ & $\begin{array}{l}\text { Agroecología, comercialización de } \\
\text { verduras y quinua, y dotación del servicio } \\
\text { de internet. }\end{array}$ & Chismaute Telán, Yacupampa \\
\hline Fundación Inti Sisa & $\begin{array}{l}\text { Cursos de perfeccionamiento educativo, } \\
\text { ecoturismo, talleres de corte confección, } \\
\text { música andina, computación y turismo } \\
\text { comunitario. }\end{array}$ & Centro cantonal de Guamote \\
\hline
\end{tabular}

Fuente: Elaboración propia a partir del trabajo de campo del autor

Con el afán de fortalecer la identidad indígena y de promover las organizaciones que apuesten por el protagonismo de los indígenas, las mencionadas ONGD, en términos generales (Tabla 1), promueven la agroecología, la misma que consiste en el cultivo de los granos andinos como la papa y la quinua; crean cadenas de comercialización entre productores y consumidores; proporcionan recursos económicos y tecnológicos para la protección de los páramos e introducen la crianza de los camélidos andinos (llamas y alpacas); erradican la violencia infantil por medio de las capacitaciones en los derechos de los niños y adolescentes, proporcionan la formación de los defensores de los derechos de los niños, entregan becas y dotan de servicios de agua; capacitan a mujeres y niños en sus derechos y en el cuidado medio ambiental; construyen escuelas y baterías sanitarias; otorgan créditos para el mejoramiento de la producción agropecuaria e instalan servicios de internet. Similar a los proyectos que ejecutan las ONGD, el Municipio de Guamote construye casas comunales, caminos vecinales, sistemas de agua entubada, baños y puentes, y la Prefectura de Chimborazo construye canales de riego y carreteras, promueve el Proyecto Sumak Kawsay financiado con los fondos de la cooperación japonesa para la implementación de invernaderos y huertos familiares. A su vez, el gobierno nacional a través del Ministerio de Desarrollo Urbano y de Vivienda ha entregado los bonos de vivienda en Gramapampa, Chuasan, Cochaloma, Yacupampa y Santa Teresita, edifica el hospital zonal y la escuela del milenio en Jatun pampa y construye el Instituto Superior Agroforestal en Palmira.

No obstante, las acciones de las ONGD y delas instituciones del gobierno indicadas anteriormente, lejos de fortalecer la identidad indígena y de articular el poder de la comunidad, repiten los mismos proyectos de desarrollo ejecutados en las décadas anteriores por el FODERUMA, el DRI, el Proyecto de Desarrollo de los Pueblos Indígenas y Negros del Ecuador (PRODEPINE), y las diversas ONGD que han desfilado a lo largo de los setenta años del desarrollo. 
De acuerdo a la evolución de los adjetivos del desarrollo, utilizados por los agentes cooperantes, pareciera que existe la ruptura con los enfoques de desarrollo y las prácticas. Sin embargo, existen la continuidad con los modos operandi del desarrollo heredados del pasado. Además, implícitamente siguen enfatizado en el crecimiento económico y en la vinculación de las comunidades con el mercado (Korovkin, 2002), aunque aludan a los derechos de los niños, los jóvenes y las mujeres; la salvaguarda del patrimonio natural y el afianzamiento de la identidad indígena como prioridades en el campo del desarrollo.

De acuerdo a los programas de intervención de las instituciones de cooperación y del gobierno, la identidad indígena está asociada directamente al campo, a las actividades agropecuarias y a la conservación de la naturaleza. Pareciera que la identidad indígena se define por la ubicación geográfica, los oficios agropecuarios y por la relación con la Pachamama (Estermann, 2014). Es como si en estos últimos años, nada hubiese cambiado en el mundo indígena, que todo se haya detenido en el tiempo. Por antonomasia para los agentes de cooperación, los indígenas son campesinos y comunitarios (Martínez, 2006). No obstante, este tipo de consideraciones ignoran las nuevas realidades a los que ellos se enfrentan (Detsch, 2018). Actualmente viven en las ciudades. El campo está habitado solamente por los adultos mayores. Según el informe del Banco Mundial Latinoamérica Indígena en el siglo XXI (2015), casi la mitad de la población indígena de América Latina vive en zonas urbanas, aunque habitan en áreas menos seguras, menos higiénicas y más propensas a desastres, en comparación con residentes no indígenas. Económicamente, los indígenas viven de las remesas enviadas por sus parientes que están en los Estados Unidos, España y en las grandes urbes ecuatorianas. Así los moradores de la comunidad Tiocajas señalan, "ya no vivimos propiamente del campo. Aquí solo hay pocas cosas y animales. Los dineros traen nuestras familiares que están en Quito y Machachi” (Entrevistados el 12.12.19).

Los indígenas en los contextos migratorios ya no son agricultores. Los descendientes de la gente que recibieron pocas tierras durante la reforma agraria (1964 - 1973), son vendedores ambulantes, comerciantes informales de verduras y frutas, albañiles (Horbart, 2008), jornaleros, ofertan en la calle accesorios de carros, y son estibadores en los mercados (Yépez, 2014). Mientras que los hijos de los que poseían más extensiones de tierra después de la reforma agraria, hoy en día, son dueños de las ferreterías, almacenes de electrodomésticos, compran y venden vehículos usados, tienen panaderías, explotan minas de material pétreo, lotizan terrenos en los sectores periféricos de las ciudades y ahorran sus ganancias económicas en las cooperativas de ahorro y crédito indígenas como Mushik Runa, Daquilema, Esencia indígena o Chibuleo, entre otros. Aquellos que han tenido la oportunidad de estudiar en las universidades, son profesores, médicos, técnicos de las ONGD, auxiliares de enfermería y políticos. Tanto los hijos de los antiguos indígenas aventajados dentro del régimen de hacienda, como aquellos que han estudiado, económicamente están en condiciones de ventaja, frente a la mayoría de indígenas que sobreviven recorriendo las calles de las ciudades y de jornaleros de las haciendas de Machachi, y que se convierten en clientes directos de los negocios establecidos por los primeros. 
En lo que respecta a la articulación de un nuevo tipo de poder, en que ya no tendría cabida la explotación de los patrones, los mayordomos y los jipus de hacienda, ni de los mestizos de los pueblos, el poder radicaría en la comunidad y en las capacidades organizativas de sus miembros. Esto sería posible, a decir de los agentes de cooperación, gracias al apoyo entregado por ellos. "Nosotros apoyamos a la organización de mujeres, fortalecimos las organizaciones comunitarias. Por nosotros existen las cajas comunales", manifiesta convencida una de las exfuncionarias de la Fundación Mujer y Familia Andina (Entrevistada el 14.12.18). Así se evidencia que las ONGD y las instituciones de gobierno, efectivamente hacen posible el surgimiento de iniciativas organizativas. Sin embargo, el establecimiento de las organizaciones, es un mecanismo de garantizar la ejecución de los proyectos de desarrollo y su concretización en el terreno. Pero los esfuerzos de los organismos de cooperación por extender las organizaciones, entran en contradicción con las dinámicas existenciales de las comunidades. Las organizaciones son impuestas por estos, sin tomar en consideración la opinión de los beneficiarios y en perjuicio de la organización comunal. Dado que las ONGD y las instituciones del gobierno exigen que los indígenas estén organizados para poder acceder a los recursos tecnológicos y económicos que ellos proporcionan, en una misma comunidad surgen el grupo de mujeres, de jóvenes, la asociación de agricultores, la caja de ahorro y crédito, el turismo comunitario, el grupo de los guardianes del páramo, la asociación de tejedoras, entre otros, cada uno en competencia permanente, y sin someterse a la autoridad del cabildo (Tuaza, 2011) que otrora velaba por toda la organización comunitaria, lideraba la solución de los problemas y administraba justicia. Los mismos miembros de la comunidad, participan de dos o tres organizaciones. Estableciendo la evaluación de los alcances de las experiencias organizativas, Manuel Atupaña, dirigente de Columbe, señalaba, "hay tantas organizaciones, la gente está cansada. Tienen que asistir a una y a otra, pero sin ningún resultado" (Entrevistado el 20.11.09). Tal como se ha demostrado en los estudios anteriores, existe el cansancio organizativo (Tuaza, 2011), una especie de agotamiento y frustración provocados por los escasos rendimientos del trabajo organizativo. “QQué beneficios tenemos de la organización? Hemos invertido mucho tiempo y recursos, sin ningún resultado" comenta Manuela Lema de Vishuk (Entrevistada el 22.12.18). A un nivel macro, la cantidad de organizaciones, provoca el fraccionamiento de las Organizaciones de Segundo Grado y el debilitamiento de las organizaciones regionales y nacionales como la Confederación de las Nacionalidades Indígenas del Ecuador (CONAIE) y el Ecuador Runakunapak Riccharimuy (ECUARUNARI), que con el correr de los tiempos, no logran articular la acción colectiva fuerte que en el pasado paralizaba al país y destituía a los gobiernos. La multitud de organizaciones promovidas por el aparato del desarrollo que sirvieron para la ejecución de las obras, divide a las comunidades, a las familias y frustran la aspiración de obtener beneficios económicos. Con el transcurso del tiempo, ninguno de los miembros se compromete a trabajar por las organizaciones. En las elecciones del cabildo u otras dignidades, los miembros rechazan ser candidatos, no reconocen ningún valor en los cargos de representación comunal. 


\section{Mecanismos de legitimación de la intervención del aparato del desarrollo}

En la mayoría de las entrevistas a los funcionarios que trabajan en las ONGD y las instituciones del gobierno, ellos nombran siempre la palabra "ayuda", cuando se refieren a las acciones que ejecutan en las comunidades indígenas. "Nosotros ayudamos", "estamos ayudando", "gracias a nuestra ayuda tienen obras", "con la ayuda nuestra sus hijos van a los estudios", "la ayuda que ofrecemos mejora la calidad de vida", "por nuestra ayuda se crearon las organizaciones", "la ayuda canalizada por nosotros promueve el turismo comunitario" ... son las expresiones que se repiten frecuentemente. Los indígenas también están convencidos de ser ayudados. "Gracias a la ayuda de las instituciones mejoramos la salud, la producción y tenemos agua en las casas", manifiestan los moradores de Chausan Totorillas (Entrevistados el 12.11.18).

El término "ayuda", procede del lenguaje religioso cristiano que expresa la posibilidad de "auxiliar", de "socorrer", "prestar cooperación", "extender la mano a las personas que están atravesando las situaciones de vulnerabilidad" (Bibliatodo, 2019), pero en el medio rural, proviene propiamente del antiguo régimen de hacienda, en el que los indígenas, al no ser dueños de la tierra, vivían en los predios de los terratenientes, trabajando gratuitamente por el pequeño lote de tierra en el que estaban edificadas sus chozas (Bretón, 2012), y cuando requerían de productos para cubrir los gastos de las fiestas, la enfermedad de un familiar y el pago de deudas, acudían al amo a solicitar el préstamo que era conocido como "ayuda", "socorro y suplido" (Lyons, 2016), por lo que quedaban con la obligación de pagar y de ser fiel al señor por el resto de sus vidas.

En kichwa, la palabra ayuda viene de la expresión yanapay, "ayuda, auxilio, socorro, favor" (Cordero, 1955: 130). Durante el funcionamiento de la hacienda, los indígenas requerían de la ayuda, el auxilio, el socorro y el favor de sus amos, pero también del favor de los familiares y de los indígenas de los llamados anejos libres, a quienes consideraban "yanapag" (Cordero, 1955). El socorro de los primeros cubría los costos de las calamidades domésticas y de los rituales religiosos, mientras que la ayuda de los segundos permitía concluir cuanto antes con las tareas asignadas en la hacienda. Por la cooperación ofrecida a los indígenas que vivían en los predios de la hacienda conocidos como huasipungueros (Rubio, 1987), los yanapagkuna o yanaperos accedían a las vertientes de agua, a la leña y al pastoreo en la basta propiedad de los amos, práctica que según Sánchez e Izurieta (2015) se habría constituido en los obrajes entre los siglos XVI y XVII. Sin embargo, los yanapakkuna al no estar directamente vinculados a la hacienda, no podían reclamar derechos de tener el huasipungo, es decir, de acceder a un lote de tierra dentro de la hacienda, tal como poseían los huasipungueros. En efecto, durante la reforma agraria, muchos de ellos no recibieron las tierras como los otros indígenas dependientes de la hacienda.

A diferencia de los yanapakkuna indígenas, los yanapag patrón, mayordomo y jipu de las haciendas aparecían revestidos de poder y de recursos, los únicos capaces de ofrecerles ayuda a los miserables indios que suplicaban favores, diciendo "patroncito no sea malito, haga el favor, he de pagar no más, ayúdenos", expresiones que recoge la novela Los ríos profundos del escritor 
peruano José María Arguedas (1958) y que permanece en el inconsciente colectivo de nuestros días, cuando solicitan un favor con la frase, "no sea malito". Quienes solicitan la ayuda se sitúan en condiciones de inferioridad, sin poder ni siquiera mirar el rostro de quien tiene y puede ayudar, pierde su condición de ser humano libre (Nagy, 2012) para aceptar cualquier clausula impuesta por aquellos que otorgan las ayudas.

La recepción de las ayudas en los latifundios serranos implicaba el intercambio de favores y gratitudes, don y deuda (Ferraro, 2004) y el aseguramiento de la permanencia de la hacienda, aun durante el auge de las reformas agrarias $(1964,1973)$. Así en las haciendas en que el grado de intercambio de favores y gratitudes era fuertes, las movilizaciones indígenas en pos de la tierra y de la libertad, conducidas por la Federación Ecuatoriana de Indios, entre las décadas de los cuarenta y sesenta no tuvieron mayor desenlace. Prueba de ello es que fueron los últimos predios en ser intervenidos por el Instituto Ecuatoriano de Reforma Agraria y Colonización (IERAC).

En el mundo de la cooperación, las ayudas recibidas implican igualmente el intercambio de favores y gratitudes, porque en los ambientes con fuerte refugio del colonialismo interno (Burgos, 1997), la idea de la ayuda capitaliza la obtención del beneplácito de los beneficiarios hacia los benefactores, que, en épocas de campaña política, si son candidatos a cargos de representación, fácilmente podrán asegurar la victoria electoral. Si no optan por la política, al menos, tendrán mayor capacidad de influencia sobre la población en los ámbitos económicos, sociales y religiosos. "Entrégales no más los picos y los azadones, ya pronto recuperaremos" es la exhortación de uno de los candidatos en el curso de las elecciones seccionales del 2014. "A ellos no hay que negar nada, hay que entregarles cualquier ayuda. Si piden cosas dadles, si piden caramelos dadles. Si ellos no reciben nuestra ayuda no nos respaldarán" son los consejos ofrecidos por el director de uno de los programas de desarrollo (Entrevistado el 15.11.18).

Si bien es cierto que la recepción de la ayuda implica el pago a corto o a largo plazo, existe el peligro de no poder pagar el favor. Esta situación conduce a los indígenas a buscar nuevos benefactores, con nuevas ayudas, ocasionado la situación de "infidelidades indígenas" de las que habla Pitarch (2003) en los casos de los indígenas del sur de México y Guatemala. Tener nuevos bienhechores implica asumir sanciones de los antiguos. Los buenos patrones de antes se convierten en los amos represivos que castigan las traiciones. "En la zona de los Galtes y los Tipines nosotros pusimos la capa asfáltica en la carretera. ¡Compañeros, así como yo les ayude, entonces, ustedes tienen que ayudarme, votando a favor de nuestro candidato!", manifiesta el Prefecto de Chimborazo. Si en los resultados de las elecciones, el candidato favorito de quien "ayudó" no resulta ser el ganador en alguna zona, durante el periodo de representación de éste la comunidad no recibe ningún apoyo. "En las elecciones seccionales de 2014, no votamos por Pachakutik, respaldamos a los candidatos de Avanza, por eso no tenemos ayudas este año. El Prefecto nos dijo, 'a ver, ustedes compañeros con qué cara vienen a pedir ayuda. Ustedes no votaron por nosotros, vayan no más a pedir a su candidato que haga obras'. Como ve, aquí no 
tenemos nada", declara el presidente de la comuna Yurak Rumi (Entrevistado el 22.08.18). En efecto, en estos últimos años, la mencionada comunidad ni otras que votaron por los candidatos de los movimientos políticos Amawta Yuyak y Avanza, no reciben los recursos económicos del Consejo Provincial, ni de las ONGD por no haber respaldado a los candidatos del partido gobernante.

El otorgamiento de las ayudas y la recepción de los dones crean las relaciones asimétricas entre quienes dan y quienes las reciben. Los receptores generalmente son considerados por los que otorgan las dádivas como gente inferior, carentes de recursos e incapaces de resolver los conflictos (Braticevic, 2011). En las comunidades de Guamote se puede encontrar con frases como estas, "sin nuestro apoyo, ellos no saldrían adelante" manifestada por una de las funcionarias de la Fundación MARCO (Entrevistada el 15.11.18). En efecto, según este criterio, los indígenas no pueden resolver sus problemas por sí mismos, carecen de la capacidad de agencia y esperan que la mano benevolente de las agencias de cooperación, las instituciones del gobierno y sus funcionarios resuelvan. Ante la mirada de los benefactores, los indígenas aparecen como seres pasivos que no mejoran las condiciones de vida. "Por más cursos que hemos dado, por más ayuda que hemos entregado, ellos (los indígenas) no entienden del aseo, del cuidado de los niños, de tener una casa limpia", considera una de las funcionarias que dirige el programa de mujeres de la Fundación Mujer y Familia Andina (Entrevistada el 22.11.18). Similar a este criterio, uno de los técnicos de Inti Sisa considera, "los indígenas no entienden del desarrollo, han dejado de lado los valores de 'ama shuwa', 'ama llulla', 'ama killa', 'no robar', 'no mentir', 'no ser ocioso' y de vivir en comunidad, los recursos económicos y tecnológicos son invertidos sin mayor efecto" (Entrevistado el 16.12.18). En esta situación de incertidumbres, la ejecución de los proyectos de desarrollo, los cursos de capacitaciones, los talleres de música y de pintura estarían orientados a dar vitalidad a la cultura indígena que está al borde de desaparecer (Inti Sisa, 2018), tal como demuestra la versión del técnico de la fundación Ayllupak tantanakuy, "hoy los indígenas están mestizándose, ya no quieren hablar el kichwa, ya no comen los granos, escuchan el reggaetón, se han vuelto corruptos, se deja llevar por los políticos y los protestantes. Que mejor que ayudemos a recuperar la cosmovisión indígena y a fortalecer lo propio" (Entrevistado el 17.11.19).

La llamada "ayuda", no solo se concreta a través de las obras que se ejecutan, sino que se legitima en el campo discursivo. A diferencia de los años ochenta y noventa, donde aparecen los adjetivos de desarrollo rural marginal, integral, sostenible, etnodesarrollo, desarrollo humano (Senn, 2000), hoy está en boga el sumak kawsay. El ideal del sumak kawsay proveniente de los actuales debates académicos en torno al desarrollo y consagrado en las constituciones de Ecuador y Bolivia, como se ha señalado anteriormente, articula los discursos y las prácticas del desarrollo de las ONGD y los organismos de gobierno en las comunidades indígenas de Guamote. Desde los letreros ubicados cerca de las carreteras y caminos vecinales, hasta los nombres de los proyectos que se ejecutan contienen el nombre de sumak kawsay. Los proyectos agroecológicos 
impulsados por el Consejo Provincial tienen el nombre de "Minga sumak kawsay", las cadenas de comercialización de la leche y quesos se conocen como emprendimientos sumak kawsay, los grupos de mujeres que trabajan con cajas de ahorro y líneas de crédito se les conoce como organizaciones de mujeres sumak kawsay, la naciente cooperativa de transportes de Colta tienen el nombre de sumak kawsay, y en ciertos casos, la palabra sumak ha sido combinado con el inglés, así el proyecto de granos andinos se le conoce como Sumak life.

Así, al incorporar la categoría del sumak kawsay al discurso y a las prácticas del desarrollo se estaría introduciendo la sabiduría y el anhelo de la vida en plenitud de los pueblos indígenas (Oviedo, 2017). “Sumak kawsay para los indígenas es su aspiración. Esta idea vamos recogiendo en los proyectos y en la ayuda que entregamos" es el criterio de uno de los funcionarios de la Fundación Heifer (Entrevistada el 16.11.18). Pero raras veces los funcionarios de las ONGD y de los organismos del gobierno preguntan por el significado real del sumak kawsay para las comunidades indígenas.

El sumak kawsay, aunque es expresión kichwa, posiblemente proveniente de la cosmovisión indígena andina y poéticamente expresiva, se convierte en una noción quelegitima la intervención de los organismos de cooperación y del gobierno, pero en el fondo, oculta el paternalismo y el racismo de las visiones y prácticas de desarrollo heredadas del indigenismo y del crecimiento económico desarrollista. "Kunanka tukuykunami sumak kawsaymanta rimankuna, shinapish imachari", "todos hablan del sumak kawsay, pero no se sabe con exactitud ¿qué mismo será?", es la preocupación de Manuel Cocha, dirigente de Zanja Loma, Cebadas (Entrevistado el 12.10.18), enunciado que coincide con lo manifestado por Bretón, Cortez y García “¿Qué cosa será el sumak kawsay?" (2014: 10).

En la reunión de los miembros de la Asociación Pulinguí San Pablo que participan del Proyecto Socio Páramo, uno de los técnicos del Ministerio de Ambiente, explica sobre las bondades de vivir en comunidad, las ventajas de cuidar el páramo, la importancia de vivir en armonía con la naturaleza y las enseñanzas de ama llulla, ama shuwa, ama killa, no ser mentiroso, no ser ladrón y no ser perezoso. Finalmente pregunta “y para ustedes ¿Qué es el sumak kawsay?” una de las participantes manifiesta en kichwa, "ña kanllatak tukuyta ninkika, imapaktak tapunki. Maypika manapish ñukanchik nishkata mirachishpapishmi ninki", "ya usted mismo dijo todo, no entiendo por qué nos pregunta. Hay cosas que no hemos dicho, pero dice usted que nosotros hemos dicho". Esta expresión de enojo, demuestra que los técnicos, no preguntan previamente a los beneficiarios de los proyectos. Ellos creen ser los portavoces de los conocimientos científicos y de los conocimientos ancestrales, con los cuales creen tener la misión de educar y de capacitar a los indígenas, que por más saberes que tengan, no estarían conscientes de lo que tienen, y si preguntan, únicamente tendrían que ratificar lo expuesto por los técnicos. "Los compañeros tienen conocimientos valiosísimos, pero no valoran. Saben de la agricultura, conocen las técnicas de conservación de los páramos, pero no son conscientes. Si tienen que quemar la paja, queman; si tienen dejar correr agua por la ladera no hacen nada, por eso nosotros estamos aquí 
para que ellos aprendan, sean conscientes de las riquezas que tienen” señala el funcionario del Ministerio de Ambiente (Entrevistado el 23.11.18). El enunciado, “¡No están conscientes!”, refleja el menosprecio del mencionado burócrata a los indígenas. Ante la mirada del técnico, mayor de edad, profesional, consciente, civilizado, mestizo o indígena estudiado, los beneficiarios son menores de edad (Adorno, 1988), menesterosos de la protección que solo ellos pueden dar.

Por su parte, los indígenas reconocen el menosprecio de los funcionarios de las instituciones de cooperación, pero no se atreven a cuestionar por temor a perder las ayudas, tal como demuestra el testimonio de las mujeres de Ishbug Curiquinga, "la ingeniera nos viene a tratarnos mal, dice que tenemos que 'hacer la planificación familiar', que tenemos wawas (hijos e hijas) como cuyes, que no sabemos alimentarnos bien. Nos damos cuenta que, en este tiempo, ya no pueden seguir tratándonos así, pero como tenemos el proyecto, mejor nos callamos" (Entrevistadas el 23.11.18). El callarse es el recurso que poseen los indígenas, a fin de garantizar la continuidad de la recepción de las ayudas, exactamente como sucedía en el antiguo régimen de hacienda, callar y someterse, aunque menosprecien y humillen.

\section{La configuración del poder y de la identidad desde el desarrollo}

Existe el criterio general entre las ONGD y las instituciones del gobierno que efectivamente sus intervenciones apoyan a la articulación de un nuevo tipo de poder, que se explicitaría en el surgimiento de las organizaciones y en el protagonismo de los indígenas en el ámbito del desarrollo. Paradójicamente, el andamiaje organizativo es una construcción, precisamente del aparato del desarrollo, tal como ha demostrado Bretón $(2001 ; 2013)$. Si bien es cierto, con la intervención de las instituciones de cooperación, aparecen varias organizaciones en una misma comunidad, compitiéndose entre ellas, estas funcionan mientras existen los recursos económicos y el tiempo en que permanecen los técnicos, posteriormente se disuelven. La desaparición de las organizaciones, desarticulan más a la debilitada organización comunal y al cabildo. En el caso de las cajas comunitarias, hay deudas que los socios mantienen, pero cuando ya no está la institución gestora, desaparecen las responsabilidades de los pagos. Esto crea resentimientos entre aquellos que pagan y aquellos que no liquidan sus deudas. Entonces, ¿Qué queda después de la desaparición de las organizaciones asociadas con la intervención de las instituciones de cooperación? El ayllu o la familia y la organización comunal, dos instituciones tradicionales, que más allá de las fronteras impuestas por las instituciones de cooperación, la política y la religión, continúan funcionando y dando respuestas a las necesidades de los indígenas.

Decir que por el apoyo recibido de las ONGD y de las instituciones del gobierno, los indígenas se convierten en protagonistas de su propio desarrollo, en parte podría ser cierto, porque proporcionan capacitaciones a sus líderes en paquetes tecnológicos, en liderazgo, en el conocimiento de la realidad nacional e internacional, la asesoría en temas de derechos y el cuidado medio ambiental, y el otorgamiento de las becas. Además, proporcionan recursos económicos que hacen posible la dotación de servicios de agua entubada, la construcción de la infraestructura educativa y de salud, los caminos vecinales. Sin embargo, son intervenciones 
momentáneas y de corto plazo. Asimismo, quienes participan de las capacitaciones y reciben las becas suelen ser personas vinculadas a las familias de los dirigentes, mientras el resto de los miembros, apenas obtienen pocos recursos.

Por otro lado, las ONGD y las instituciones del gobierno presumen de haber realizado las obras, cuando quienes realizan el trabajo en cuanto tal, son los propios beneficiarios. La participación en el trabajo comunitario o la minka, la asistencia a las reuniones y a las capacitaciones, la contribución económica de cada uno de los beneficiarios es escasamente valorados y contabilizados económicamente por las instituciones de cooperación. Cuentan el dinero y el tiempo invertido por los cooperantes, pero no el esfuerzo de la comunidad. La evidencia empírica indica que el éxito de la ejecución de los proyectos, depende de la acción de los mismos beneficiarios. Los recursos que entregan las instituciones sirven de estímulo para activar la minga en que interviene la comunidad entera. En este sentido Manuel Sayay, presidente de Pull Grande manifiesta, "estamos agradecidos con la institución, pero el trabajo hemos hecho nosotros. Los técnicos entregaron ladrillos, cemento y hierro. La comunidad compró el material pétreo, el techo, las ventanas, las puertas y la mano de obra" (Entrevistado el 30.11.18). Por su parte, Polinario Sagnama de la misma comunidad, dice, "con institución o sin institución, con ayuda o sin ayuda nosotros continuaremos viviendo" (Entrevistado el 30.11.18).

En efecto, las comunidades han desarrollado otras estrategias de supervivencia y de resolución de los conflictos. En los contextos migratorios, donde hoy en día residen los indígenas, no existe el apoyo directo de las ONGD. La familia y la red de familias que se entretejen en las ciudades, permiten a los recién llegados a la ciudad insertarse en la vida urbana, obtener trabajo y sentirse apoyados. Los familiares otorgan préstamos económicos que son invertidos en los pequeños negocios, ofrecen oportunidades laborales en las panaderías, en las minas y otro tipo de emprendimientos, aspectos que requieren ser estudiados.

Llama la atención cómo los funcionarios de las ONGD y las instituciones del gobierno local, provincial y nacional insisten en que las acciones emprendidas por sus instituciones en pos del desarrollo son "ayudas" (Tuaza, 2014). ¿Quién puede ayudarles? El mundo indígena profundamente religioso va a responder a este interrogante, "tayta Dios, tayta amito". En el tiempo de la hacienda, el hacendado, el cura párroco y los mestizos del pueblo eran considerados tayta amitos (Arrieta, 1984). Los favores otorgados por estos, eran concebidos como ayudas. El término tayta, papá supone respeto y cariño, pero también infunde temor. Hoy en día, los tayta amos pueden ser también los indígenas ricos, estudiados, pastores evangélicos, técnicos de las ONGD y del gobierno, médicos y políticos (Tuaza, 2017). Estos nuevos amos creen tener la solución a los males que padece "la desgraciada raza indígena", tal como dijo en sus días Pío Jaramillo Alvarado (1988). Gracias a la mano benevolente de los nuevos amos, por fin los indígenas pobres serán conducidos al paraíso terrenal, prometido por el credo religioso desarrollista (Esteva, 2009). 
Ante la mirada de los nuevos amos indígenas, asimismo de los amos mestizos, muchos de ellos descendientes y herederos de los antiguos amos, convertidos ahora en funcionarios de las ONGD y de las instituciones del gobierno, los indígenas no son ciudadanos, no tienen derechos. Simplemente esperan regalos y posteriormente pagar los favores. Además, los amos piensan que los indígenas son propiedad de ellos. En las entrevistas realizadas a los funcionarios, es común encontrar con la expresión "nuestros indígenas", "acompañamos a nuestros indígenas", “apoyamos a nuestros indígenas". Pero el apoyo, igualmente puede ser algo simbólico como la entrega de caramelos en tiempos de las festividades de la navidad. Bastará un poco de dulces para garantizar la fidelidad de la comunidad a una persona o a un organismo de cooperación. Esta situación evidencia que aquel sueño de la superación de las antiguas ventriloquías (Guerrero, 2010), fruto de la fuerte acción colectiva desatada por el movimiento indígena en los noventa, aun no se concreta. Hay nuevas ventriloquías articuladas por los nuevos amos que he señalado anteriormente.

En un contexto social, cultural y económico de intercambio de favores y gratitudes entre los amos y los súbditos, no es posible en términos políticos, hablar de la construcción del poder que involucre a toda la comunidad. Se resignifica el poder pastoral, del que nos habla Michael Foucault (1988). Quienes manejan el poder, en este caso los amos en calidad de pastores, marcan las pautas de acción, el resto son fieles, prestos a escuchar, obedecer y a agradecer. Estos últimos, que, en comparación con los amos, no tienen derechos, simplemente son clientes, pobres que requieren de la ayuda, no pueden reclamar, ni exigir cuentas. En efecto, la rendición de cuentas (Levine y Molina, 2011), sigue causando temor a los funcionarios, a los técnicos y en sí a las ONGD e instituciones del gobierno que operan en el medio rural guamoteño. "Nosotros somos una institución cristiana, nosotros hacemos caso las enseñanzas de Jesús que dice 'que la mano derecha no sepa lo que hace tu izquierda', por esta razón damos comprando las cositas. Nuestro director tiene alianzas estratégicas de cómo pagar los útiles escolares en las grandes librerías de Riobamba, y que nuestros indígenas reclamen con su nombre los útiles. Todo está en el sistema. Con su ticket retiran la lista de útiles", manifiesta el funcionario de Compasión Internacional (Entrevistado el 12.11.18). Otro de los funcionarios considera, "la rendición de cuentas es propia del municipio y de las instituciones del gobierno. Nosotros somos institución de ayuda social que estamos exentos de rendir cuentas. La gente no tiene por qué saber cuánto de dinero recibimos y entregamos. Ahí están las obras. Si hay duda reclamen a sus directivos" (Entrevistado el 14.11.18). La ausencia de la rendición de cuentas crea sospechas, desintegra a las familias y a las comunidades, consecuentemente, la organización comunal y las iniciativas del desarrollo fracasan.

En un mundo cada vez cambiante, donde la identidad se construye y deconstruye, donde se exalta al individuo sobre la comunidad, lo económico por encima de otras experiencias existenciales, es menester promover el trabajo para el desarrollo en sintonía con los pueblos indígenas, escuchar sus propuestas, aprender de sus vidas, conocer las maneras de resolución de 
conflictos que poseen. Pero este proceso debe ir acompañado por una crítica permanente que dude de los neologismos del desarrollo, que, aunque estén escritos en las lenguas originarias, en el fondo pueden estar cubiertos de ropajes coloniales que discriminan y menosprecian a los pueblos indígenas.

Por otro lado, no es suficiente incorporar neologismos del desarrollo, con expresiones aparentemente provenientes de los pueblos indígenas, sin antes haber estudiado y comprendido el significado profundo de las palabras como el sumak kawsay para las comunidades indígenas. “QQué es eso del sumak kawsay?” es el interrogante que aparece con frecuencia en las comunidades. Pero, ¿existe realmente la voluntad política de los agentes de cooperación por aprender de los pueblos indígenas? ¿Existen estudios que visibilicen la capacidad de resolución de los conflictos que tienen los indígenas? La evidencia empírica nos demuestra que las instituciones de cooperación y sus funcionarios, al considerarse que ellos son los portadores de los conocimientos tecnológicos y los recursos económicos, que han recibido la misión secular de educar y civilizar a los pueblos indígenas que desconocen de la vida y de las ventajas de ser desarrollados, no se toman la molestia de aprender los conocimientos locales, ni las experiencias previas de trabajo en desarrollo. Van a las comunidades con recetas de intervención elaboradas en la ciudad y con visión puramente tecnológica, por la cual invisibilizan los conocimientos y saberes importantes (Escobar, 2012). De este modo, al llegar al campo, sacrifican, según Gustavo Esteva "entornos, solidaridades, interpretaciones y costumbres tradicionales en el altar de la siempre cambiante asesoría de los expertos" (2009: 2), que crean y consolidan las formas de dominación que existen hoy en día.

\section{Conclusión}

A manera de conclusión se puede señalar que la intervención de las ONGD y las instituciones del gobierno local, provincial y nacional, aunque tengan sus programas y sus discursos en kichwa, utilicen los diversos adjetivos del desarrollo, como por ejemplo, el sumak kawsay, trabajen por la actividad agropecuaria y la salvaguarda del medio ambiente, capaciten en los derechos de las mujeres, de los niños y jóvenes, acciones entendidas por estas como ayudas, no contribuyen lo suficiente al fortalecimiento de la identidad indígena, ni a la articulación de un nuevo tipo de poder que se explicitaría en el surgimiento de las organizaciones y en el protagonismo de los indígenas en pos del desarrollo. En contrate, con las llamadas ayudas resignifican las antiguas formas de dominación heredadas del pasado colonial y del régimen de hacienda, fortaleciendo la capacidad de maniobra de quienes manejan los recursos de cooperación sobre las comunidades indígenas. 


\section{REFERENCIAS BIBLIOGRÁFICAS}

Acosta, Alberto (2009) La maldición de la abundancia. Quito: Comité Económica de Proyectos, Swissaid y Abya Yala.

Acosta, Alberto (2010) "Respuestas regionales para problemas globales". En Irene León (coord) Sumak Kawsay/Buen Vivir y cambios civilizatorios. Quito: FEDAEPS, pp. 89-103.

Acosta, Alberto (2011) "Extractivismo y neoextractivismo: dos caras de la misma maldición". En Miriam Lang y Dunia Mokrani (comp.) Más allá del desarrollo. Quito: Abya Yala, Fundación Rosa Luxemburg, pp. 83-118.

Adorno, Rolena (1988) "El sujeto colonial y la construcción cultural de la alteridad". En Revista de Crítica Literaria Latinoamericana 14, (28), pp. 55-68.

Arguedas, José María (1958) Los ríos profundos. Buenos Aires: Editorial Losada.

Arrieta, Modesto (1984) Cacha cuna de la nacionalidad ecuatoriana. Riobamba: FODERUMA.

Banco Mundial (2015) Latinoamérica Indígena en el siglo XXI. http://documents.worldbank. org/curated/en/541651467999959129/pdf/98544-WP-P148348-Box394854B-PUBLICLatinoamerica-indigena-SPANISH.pdf (Consultado el 22 de noviembre de 2018).

Bebbintong, Anthony y Torres, Víctor (2001) Capital social en los Andes. Quito: Abya Yala.

Bibliatodo (2019) Diccionario. https://www.bibliatodo.com/Diccionario-biblico (Consultado el 20 de diciembre de 2018).

Braticevic, Sergio (2011) "El papel de las ONG en proyectos de desarrollo en una formación social de fronteras. El caso del programa DIRLI en el oeste formoseño". Revista Intersecciones en Antropología 12, (1), pp. 135-146.

Bretón, Víctor, Cortez, David y García, Fernando. (2014) “En busca del sumak kawsay”. Íconos 48, pp. 9-24.

Bretón, Víctor (2001) Cooperación al desarrollo y demandas étnicas en los Andes ecuatorianos. Quito: FLACSO.

Bretón, Víctor (2012) Toacazo. En los Andes equinocciales tras la Reforma Agraria. Quito: Abya Yala.

Bretón, Víctor. (2013) "Etnicidad, desarrollo y 'Buen Vivir': Reflexiones de contenido en perspectiva histórica”. Revista Europea de Estudios Latinoamericanos y del Caribe 95, pp. 71-95. Burgos, Hugo (1997) Relaciones interétnicas en Riobamba. Quito: Corporación Editora Nacional. Cordero, Luis (1955) Diccionario Quichua-Castellano. Quito: Casa de la Cultura Ecuatoriana. Cuestas-Caza, Javier (2018) El sumak kawsay. El Buen Vivir antes de ser buen vivir. https://www. academia.edu/33156575/ (Consultado el 21 de octubre de 2018). 
Detsch, Claudia (2018) Transformación social-ecológica del sector agrario en América Latina. Pasos y actores claves. Buenos Aires: Friedrich Ebert Stiftunng y Nueva Sociedad.

Escobar, Arturo (2012) "Más allá del desarrollo: Postdesarrollo y transiciones hacia lo pluridiverso". Revista de Antropología Social 21, pp. 23-62.

Esteva, Gustavo (2009) "Más allá del desarrollo: la buena vida". Revista América Latina en movimiento. https://www.alainet.org/es/active/38110. (Consultado el 14 de noviembre de 2018).

Estermann, Josef (2014) Cruz \& Coca: hacia la descolonización de religión y teología. Quito: Abya Yala.

Ferraro, Emilia (2004) Reciprocidad, don y deuda. Formas y relaciones de intercambio en los Andes de Ecuador: la comunidad de Pesillo. Quito: FLACSO.

Foucault, Michel (1988) “El sujeto y el poder”. Revista Mexicana de Sociología 50(3), pp. 3- 20.

FUNDAMYF (2007) Condiciones meteorológicas del cantón Riobamba y Colta. https://issuu. com/nesster/docs/case_study_fundamyf (Consultado el 13 de noviembre de 2018).

Gudynas, Eduardo (2017) “Extractivismo y corrupción en América del Sur”. RevIISE 10, pp. 73-87.

Guerrero, Andrés (2010) Administración de poblaciones, ventriloquia y transescritura. Quito: FLACSO, IEP.

Horbart, Jorge (2008) "La discriminación laboral de los indígenas en los mercados urbanos de trabajo en México: revisión y balance de un fenómeno persistente”. En Fernando García (Comp.), Identidad, etnicidad y racismo en América Latina. Quito: FLACSO, Ministerio de Cultura, pp. 121-158.

Ibarra, Hernán (2002) “Gamonalismo y dominación en los Andes”. En Iconos 14, pp. 137-147. Inti Sisa (2018) Fundación, historia y visión. http://www.intisisa.org/IS2013/SP/geschiedenis. html (Consultado el 24 de noviembre de 2018).

Jaramillo, Pío (1988) “El indio ecuatoriano”. En Claudio Malo (Ed.), Pensamiento indigenista del Ecuador. Quito: Corporación Editora Nacional.

Korovkin, Tanya (2002) Comunidades indígenas: economía de mercado y democracia en los Andes ecuatorianos. Quito: Abya Yala, IFFA, CEDIME.

Larrea, Ana (2010) "La disputa de sentidos por el buen vivir como proceso contrahegemónico". En AAVV Socialismo y sumak kawsay. Los nuevos retos de América Latina. Quito: SENPLADES. León, Irene (2010) “Resignificaciones, cambio societales y alternativas civilizatorias". En Irene León (coord), Sumak Kawsay/Buen Vivir y cambios civilizatorios. Quito: FEDAEPS, pp. 7-12.

Levine, Daniel, y Molina, Enrique (2011) "Calidad de la democracia: fortalezas y debilidades en América Latina”. Revista Latinoamericana de Política Comparada 5, pp. 95-123. 
Lyons, Barry (2016) Sociedad, historia e interculturalidad en Chimborazo. Quito: Abya Yala y Wayne State.

Martínez, Carmen (2006) Who defines indigenous? Identities, development, intellectuals and the state in Northern Mexico. New Brunswick, New Jersey and London: Rutgers University Press.

Nagy, Mariano (2012) "Circulación e incorporación en la frontera: Trayectorias indígenas tras la "Conquista del desierto". Revista Mundo Nuevo, Mundos Nuevos. https://journals.openedition. org/nuevomundo/64156. (Consultado el 15 de enero de 2019).

Oviedo, Atawalpa (2017) "Que es el buen vivir (Sumak Kawsay). Rebelión. http://www.rebelion. org/noticia.php?id=231005. (Consultado el 18 de enero de 2019).

Palenzuela, Pablo (2011) “Discursos y prácticas del desarrollismo en los Andes ecuatorianos: el proyecto PRODECO en Cotopaxi”. En Pablo Palenzuela y Alessandra Olivi (coord.), Etnicidad y desarrollo en los Andes. Sevilla: Universidad de Sevilla, Secretariado de Publicaciones.

Pitarch, Pedro (2003) “Infidelidades indígenas”. Revista de Occidente, 270, pp. 60-75.

Prada, Raul (2011) "El vivir bien como modelo de Estado y modelo económico". En Miriam Lang y Dunia Mokrani (Comp.), Más allá del desarrollo. Quito: Abya Yala, Fundación Rosa Luxemburg, pp. 21-53.

Ramírez, René (2010) “Socialismo del sumak kawsay o biosocialismo republicano. En SENPLADES, Socialismo y sumak kawsay. Los nuevos retos de América Latina. Quito: SENPLADES, pp. 55-76.

Sánchez, D., Izurieta, X. (2015) “Sistema de yanapa y antropización de los páramos ecuatorianos”. En Unión Internacional para la Conservación de la Naturaleza. https://www.portalces.org/ fuente/uicn-sur/sistema-de-yanapa-antropizacion-de-paramos-ecuatorianos. (Consultado el 22 de enero de 2019).

Rubio, Gonzalo (1987) Los indios ecuatorianos. Evolución histórica y políticas indigenistas. Quito: Corporación Editora Nacional.

Santana, Roberto (1995) Ciudadanos en la etnicidad: los indios en la política o la política de los indios. Quito: Abya Yala.

Senn, Amartya (2000) Desarrollo y libertad. Buenos Aires: Editorial Planeta.

Simbaña, Floresmilo (2011) "El sumak kawsay como proyecto político". En Miriam Lang y Dunia Mokrani (comp.) Más allá del desarrollo. Quito: Abya Yala, Fundación Rosa Luxemburg, pp. 219-226.

Tuaza, Luis Alberto (2011) Runakunaka ashka shaikuska shinami rikurinkuna, ña mana tandanakunata munankunachu: crisis del movimiento indígena ecuatoriano. Quito: FLACSO.

Tuaza, Luis Alberto (2014) "La continuidad de los discursos y prácticas de la hacienda en el 
contexto de la cooperación”. Revista de Antropología Social 23, pp. 117-135.

Tuaza, Luis Alberto (2017) “Liderazgo indígena tras la disolución de la hacienda”. En Ecuador Debate 102, pp. 33-44.

Viola, Andreu (2014) "Discursos "pachamamistas" versus políticas desarrollistas: el debate sobre el sumak kawsay en los Andes. Íconos 48), pp. 55-72.

Yépez, Pascual (2014) La vida de los indígenas en la ciudad de Quito. Quito: Imprefepp. 